\title{
Temporalidades críticas: el caso de Douglas Gordon
}

\section{Critical Temporalities: The Case of Douglas Gordon}

\author{
Jesús Segura-Cabañero \\ Universidad de Murcia \\ jesusegu@um.es
}

Recibido: 04 de noviembre de 2012

Aprobado: 24 de marzo de 2013

\section{Resumen}

El presente texto analiza la temporalidad de la imagen en movimiento y su manipulación como recurso conceptual en la obra de Douglas Gordon. El análisis se fundamenta en las características específicas del tipo de producción artística de los nuevos medios basados en el tiempo, es decir, aquellas obras de arte que dependen de la tecnología y la duración temporal como dimensión interpretativa. La intención de este artículo es reflejar y debatir las distintas temporalidades que aparecen en la obra de Gordon y desvelar las conexiones entre sus recursos temporales y la crítica ideológica. Así, en un primer momento se explora la relación entre la percepción y el lenguaje, para pasar después a considerar la dilatación del tiempo y el desplazamiento del foco de atención como instrumentos de exhibición en su obra. Ésta nos desvela unas interrelaciones de carácter contextual e ideológico.

Palabras clave: Temporalidad, percepción, Douglas Gordon, ideología, video instalación.

Segura Cabañero, J (2013): Temporalidades críticas: el caso de Douglas Gordon. Arte, Individuo y Sociedad, 26 (1) 54-66

\begin{abstract}
This paper analyzes the temporality of the moving image and its manipulation as conceptual resource in the work of Douglas Gordon. The analysis is based on the specific characteristics of the type of artistic production of the time-based new media, i.e. those artworks that rely on technology and the temporal duration as interpretive dimension. The intent of this article is to reflect and discuss the different temporalities that appear in the work of Gordon and reveal the connections between their temporary resources and ideological critique. So, at first explores the relationship between perception and language to go on considering the slowing down of time and the shift of focus of attention in his work that reveals relationships of ideological and contextual type.
\end{abstract}

Key words: Temporality, perception, Douglas Gordon, ideology, video installation.

Segura Cabañero, J (2013): Critical Temporalities: The Case of Douglas Gordon. Arte, Individuo y Sociedad, 26 (1) 54-66

Sumario: 1. Introducción 2. Exploración de anomalías semánticas 3. Expansión temporal de la película 4. El desplazamiento del foco de atención 5. Conclusiones. Referencias. 
Este trabajo se incorpora al conjunto de investigaciones propuestas por el proyecto de investigación: "Temporalidades de la imagen: heterocronía y anacronismo en la cultura visual contemporánea" Ref. HAR-2012-39322. El articulo está financiado con cargo al programa de la Dirección General de Investigación y Gestión del Plan Nacional I+D+I de Proyectos de Investigación del Ministerio de Economía y Competitividad.

\section{Introducción}

El presente estudio tiene como punto de partida la investigación del concepto de la temporalidad en la obra de diferentes artistas que incorporan el proceso del tiempo como eje medular de sus propuestas. Estas temporalidades de la imagen abordan la centralidad del tiempo como problema en el arte, la cultura visual y el pensamiento de la contemporaneidad. A través de diferentes casos de estudio, se intenta explorar los modos en los que las alteraciones recurrentes de la temporalidad constituyen modalidades de resistencia ante una concepción del tiempo y la historia. Las transformaciones y convulsiones de la imagen sometidas a arquitecturas temporales diversas proporcionarán un punto de encuentro con investigaciones paralelas de investigadores de diversas disciplinas que conforman un proyecto multidisciplinar más amplio recogido en el proyecto de investigación "Temporalidades de la imagen: heterocronía y anacronismo en la cultura visual contemporánea" dentro de marco de proyectos de investigación I+D+I del Ministerio de Economía y Competitividad.

Este artículo explora desde parámetros temporales y críticos la obra de un artista que ha hecho de la temporalidad, el objeto de análisis e intervención en su producción artística, como es el caso del trabajo de Douglas Gordon. Una de mis aportaciones al proyecto de investigación mencionado, ahonda en el estudio y clasificación de una serie de autores-productores artísticos que incorporan estrategias artísticas donde la manipulación de las tecnologías de la imagen desnaturaliza los ritmos temporales cotidianos y mediáticos para producir perturbaciones en la percepción y recepción de las imágenes. El caso de Douglas Gordon ha sido tratado desde múltiples puntos de vista, que recorren un nexo crítico y reflexivo con diferentes recursos que van desde el tratamiento de la imagen cinematográfica, pasando por la exploración de la memoria colectiva - mediante elementos reales y ficcionales - hasta cuestiones espaciotemporales que cuestionan la construcción de los relatos impuestos. Sin embargo, en contadas ocasiones se hace referencia a la relación implícita que existe en sus trabajos entre temporalidad e ideología. El propósito de este artículo es reflexionar y establecer las conexiones precisas entre las distintas temporalidades de la imagen insertadas en sus obras y las formaciones ideológicas que se desprenden de la intervención del tiempo en ellas.

El trabajo de Douglas Gordon presenta también una preocupación central en la alteración temporal de la visualidad, en el despliegue de estrategias perceptivas que contravienen las lógicas de consumo y capitalización, cada vez más presentes en la sociedad actual. Lipovestsky (Lipovetsky y Charles, 2006) expone como nuestra época se caracteriza por el hiperconsumo y el individuo hipermoderno, donde la angustia, el miedo y la ansiedad se han revelado como estigmas del sujeto contemporáneo. Estas consecuencias de raíz emocional son incorporadas en las piezas de Douglas Gordon como cuestiones esenciales en sus propuestas. El desarrollo de es- 
tos elementos se articula mediante una "forma-polémica", desarrollando variables de "opuestos" que presentan conceptos dialógicos. La obra de Douglas Gordon recrea de manera literal ese diálogo entre lo personal y lo histórico, entre la memoria y la imaginación, la ficción y la realidad. Como ha señalado Rosalyn Krauss:

La lógica espacial de la práctica posmodernista ya no se organiza alrededor de la definición de un medio dado sobre la base del material o de la percepción de este, sino que se organiza a través del universo de términos que se consideran en oposición dentro de una situación cultural. (Krauss, 1998, pp. 72-73).

La incorporación de recursos técnicos que aceleran, interrumpen, desnaturalizan $\mathrm{y}$ trastornan los ritmos temporales cotidianos para producir perturbaciones en la percepción de las imágenes es fruto de un proceso crítico llevado a cabo por el artista. En un afán de elaborar modos de resistencia que construyan instrumentos enunciativos que sean capaces de reconfigurar material y simbólicamente un territorio. Entregado completamente a una estetización impuesta por el hiperconsumo. Su trabajo ejecuta esta alteración de la percepción sobre tres presupuestos:

- La exploración de las anomalías semánticas.

- La expansión temporal del film.

- El desplazamiento del foco de atención.

En este sentido, el magnetismo de sus trabajos obedece a una persuasión explícita que tiene mucho que ver con una internalización psico-social de la precariedad de los modos de vida del individuo contemporáneo; donde los elementos puestos en juego en la representación adquieren una lógica entre el desasosiego y la extrañeza. La conjugación de estas atmósferas se efectúa mediante la inserción de "vacíos" y "desconexiones" entre los elementos dispuestos en la representación; permitiendo configurar ese espacio de análisis crítico al que Gordon somete sus imágenes. Como apunta Susan Buck-Morss: "La fuerza de la imagen surge cuando se desprende de su contexto. No pertenece a la forma mercancía, aunque se encuentre -incidentalmentebajo esa forma (como en la publicidad)". (Buck-Morss, 2005, p. 157).

El interés de Gordon se centra en elaborar un imaginario que no difunde sentencias críticas, sino que, nos sitúa en una inmersión visual mediante la cual observamos y construimos nuestras realidades críticamente. En este sentido su trabajo podría enmarcarse en una modalidad de reflexión crítica acerca del mundo. Por tanto, estamos hablando de un arte que produce, piensa y reflexiona; que genera conocimiento acerca del mundo (Bal, 2001). Y de esta manera, el artista está situado al nivel del pensador.

Es por esto que, el discurso crítico aliado a la práctica artística conjuga un territorio de resistencia frente a la programática emocional del tardo-capitalismo. Así, la obra de arte, mediante la suspensión de significados implícitos, mediante la disolución de las prácticas del shock, reafirma el estatuto del disenso y la experimentación crítica que se produce entre obra y espectador, separándose así definitivamente, de cualquier interés de transformación social que pueda ser engullida por las maquinarias legitimadoras y perpetuadoras del poder hegemónico. 


\section{Exploración de las anomalías semánticas}

Dentro de esa exploración de las anomalías semánticas desarrolladas en el trabajo de Douglas Gordon, se observa la puesta en crisis del tiempo lineal y monocrónico de la modernidad, a través de toda una serie de alteraciones, desnaturalizaciones y revisiones que configuran un espectro visual, donde la relación entre lenguaje y percepción activa resortes cognitivos sometidos a la subjetividad del espectador.

Quizá, el trabajo que mejor recoge este axioma sea From God to Nothing (De Dios a nada) (1996). Una instalación que incluye un texto en blanco que recorre las paredes de una sala, configurando un movimiento circular en torno a ella. La sala esta pintada de color azul oscuro e iluminada por tres bombillas, dispuestas en escala humana a tres alturas distintas: a la altura de la cabeza, la del corazón y la de los genitales, señalando los textos que narra la mente, el cuerpo y el sexo. Los textos comienzan con el "Miedo a Dios" y concluyen con el "Miedo a la nada" y, en este tránsito, se mencionan ciento cuarenta y siete miedos entre los que se encuentran: "el miedo al amor", "el miedo a la muerte", "el miedo a caer", etc.

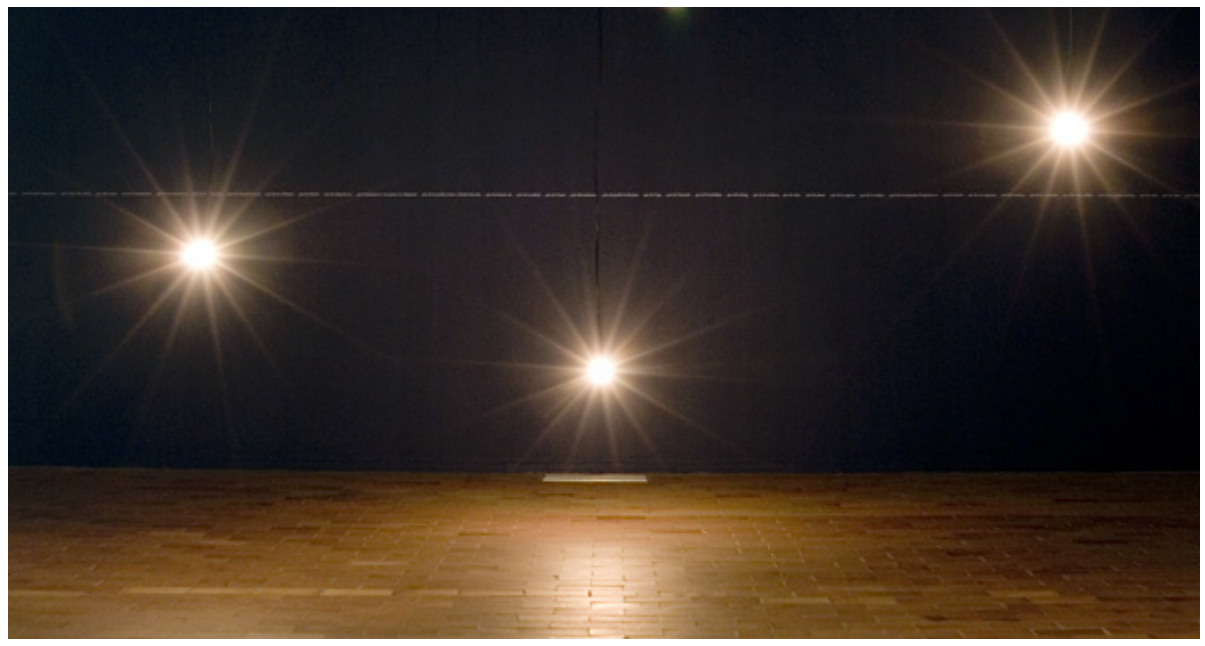

Figura 1. Douglas Gordon, From God to Nothing, 1996

(Imagen recuperada de Internet, de: http://www.moisdelaphoto.com/gordon_en.html)

La relación entre lenguaje e imagen y los conceptos de luz y oscuridad coinciden con procesos psicológicos, donde se da entrada a un "juego entre contrarios", donde la forma-escenario asume lo cognitivo como elemento configurador. Y, de este modo, activa la esencia de nuestras propias contradicciones. De alguna manera, esa exploración de las anomalías semánticas fractura la homogeneización de la existencia que pretende reducirlo todo a una sola explicación. Lo que quiero decir es que Gordon, a través de escenarios cognitivos, plantea la dualidad como principio y final de toda experiencia. Y esto lo hace dejando al espectador, al visitante de su instalación que construya el sentido de la obra. Articulando un sistema de ejecución donde los dispositivos creativos son reinventados in situ. Configurando una co-presencia que va a 
tener divergencias entre obra plástica y espectador. Así, se establece una negociación intersubjetiva donde la obra adquiere el carácter de acontecimiento.

Alain Badiou (Badiou, 1999) define un acontecimiento como un "singular-universal", un hecho que se ejecuta en una historia particular pero que es extensible a una pluralidad de relaciones universales donde la construcción de sentido es siempre intersubjetiva. Este pensamiento-acontecimiento, vehicula psíquicamente al visitante hacia un activismo fenomenológico. Tal y como indica Rancière:

En el arte relacional, la creación de una situación indecisa y efimera requiere de un desplazamiento de la percepción, un cambio del estatuto del espectador por el de actor, una reconfiguración de los lugares [...] lo propio del arte consiste en practicar una distribución nueva del espacio material y simbólico. Y por ahi es por donde el arte tiene que ver con la política. (Rancière, 2005, p. 17).

En efecto, en From God to Nothing (De Dios a nada) (1996) podemos considerar que la exposición se ha convertido en plató, articulando modelos de relación con los espacios y tiempos que otorgan al visitante-actor la capacidad de producir intercambios que generan sentido. En definitiva, la configuración de relaciones que se efectúan en el espacio dado por el artista está íntimamente relacionada con la asunción por parte del visitante-actor de procesos de enunciación de significado y, por tanto, con una forma de acercamiento a las cuestiones artísticas con un fuerte poso participativo.

Tenemos que convenir, entonces, que una de las funciones del artista es temporalizar las mecánicas de producción para ampliar significados implícitos. Reinventar y ampliar los modos de experimentación de lo real, a través de elementos dados cuya retícula está formulada en parámetros de laboratorio de experimentación de modos de vida. Llegados a este punto hay que negociar con Bourriaud (Bourriaud, 1998, pp. 112120) que el problema, entonces, reside en la subjetividad. En los procesos y unidades de subjetivización presentes en la instalación de Douglas Gordon. A este respecto, el espacio de intercambio que propone Douglas Gordon con From God to Nothing (De Dios a nada) (1996) desarrolla tácticas que tienen en cuenta el "texto" y el "contexto", subvirtiendo sus significados. Con lo cual, habría que preguntarse por una manera de habitar esta pieza bajo miradas múltiples y variadas, donde la imaginación del visitante escruta lo real. $\mathrm{Y}$ en esa negociación se producen intercambios de variables de sentido. El sentido, tal y como apunta Bourriaud: "[...] es el producto de una interacción entre el artista y "el que mira", y no un hecho autoritario". (Bourriaud, 1998, p. 123).

Por tanto, de lo que estamos hablando es de la configuración semiótica de la representación para un desmantelamiento del espacio de producción estética, en favor de un espacio de producción de sentido. Así, la recreación de la "idea" por parte del receptor se convierte en un juego de composición e interpretación adscrito a un contexto específico donde se produce un debate. En este contexto, la creación de vínculos para producir relaciones y pensamiento con el mundo, y acerca de este, depende en última instancia del visitante, del espectador, de las audiencias. 


\section{Expansión temporal de la película}

El "Expanded Cinema" (Cine Expandido), describe todo lo que va más allá de las habituales tecnologías de producción y proyección del cine, fracturando la narratividad literaria y estática de la imagen única del cine e incorporando recursos visuales que amplían y cuestionan los espacios de exhibición y las técnicas de montaje y distribución. El cine y las instalaciones audiovisuales son el medio que emplea Douglas Gordon. Sus intervenciones en piezas cinematográficas clásicas y sus propias producciones, que se caracterizan por manipular la percepción visual de la película estableciendo operaciones artísticas, van desde la apropiación, la manipulación y la deconstrucción fílmica mediante recursos temporales aplicados a la proyección (escala y disposición espacial), hasta la manipulación de la estructura de la película para descargar en la subjetividad del espectador toda producción de sentido.

Sin embargo, las construcciones temporales que nos interesa someter a debate aquí tienen que ver con la prolongación del tiempo en la película, así como, con el propósito de confrontar el momento de la narración fílmica y la extensión del tiempo en la película. Estas incorporan el tiempo real de la instalación y la subjetividad del espectador en esa recepción. A este respecto, Daniel Birbaum (Birbaum, 2005) propone el tiempo del espectador y el tiempo de la imagen de manera literal como recurso para vaciar de sentido la obra y la carga simbólica contenida en ellas, generando una nueva cronología. Esto recrea un constante anacronismo del tiempo que viene dado por la utilización en el caso de Gordon de la figura de Hicthcock, incorporando un carácter icónico, que refleja de manera ejemplar este anacronismo. El caso más representativo es 24 Hour Psycho (1993). Esta obra consiste en la manipulación de la película de Alfred Hitchcock Psicosis (1960). Gordon ralentiza la duración original de la película (109 minutos) ampliando el tiempo de duración de la misma durante veinticuatro horas. Este proceso bastante simple, revela sin embargo un complejo mecanismo de memoria en el espectador, produciendo un anacronismo visual y temporal que permite un vacío de sentido en la obra.

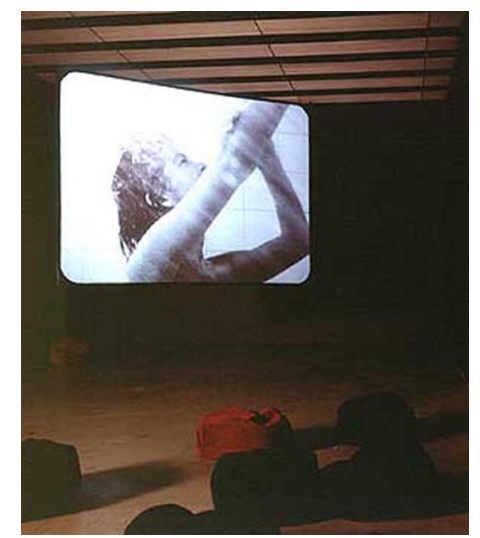

Figura 2. Douglas Gordon, 24 Hour Psycho, 1993.

(Imagen recuperada de Internet, de: http://www.moisdelaphoto.com/gordon_en.html) 
Lo que Gordon pretende con esta alteración temporal, al alargar las escenas, es quitar la tensión inmediata que se produce en ellas, es decir, desdramatizar la película. De este modo, juega con la expectación, la memoria y el miedo convertido ahora en soporífera espera del espectador. Al desnaturalizar y dilatar la película hace emerger una narrativa que opera sobre los cambios sobredimensionados en la textura de la imagen. Igualmente, al utilizar un clásico del cine de Hollywood, la narración no sólo está en la instalación misma, sino en la mente del espectador que incorpora sus registros y activa un constante anacronismo en la pieza. Tal como escribe Klaus Biesenbach: "él explora el modo en que nuestros recuerdos visuales se conforman por eventos reales y ficcionales, por la textura entretejida de tramas imaginadas y recolectadas, y por lo que recordamos y lo que creemos recordar. Su obra toma como punto de partida la percepción y la memoria”. (Biesenbach, 2007).

Al variar el ritmo normal de la película de veinticuatro fotogramas por segundo a dos fotogramas se produce una inversión, un vacío simbólico que modifica la forma de ver, la forma de pensar del espectador, y por tanto, trastoca la recepción e intensidad de lo percibido provocándole una constante huida del pasado al futuro y viceversa. De alguna manera Gordon recluye al espectador dentro de un esquema de expresiones y gestos congelados, creando un sistema de referencias afectivas que conecta a los actores de la película y a los espectadores del remake. Gordon extrae elementos sintomáticos de una película que actúan como una piedra de toque para nuestros supuestos culturales.

Mieke Bal (Bal, 2009) ha descrito certeramente el mecanismo de formación de la narración en la mente del espectador como un ejercicio de montaje, donde distingue una homología lingüística y una homología estructural, que emergen a la superficie cuando se fractura una historia en categorías de eventos. En 24 Hour Psycho (1993), la alteración temporal a la que es sometida la película de Alfred Hitchcock fractura el relato. Y como consecuencia de esa hibridación múltiple, revela la aparición de heterocronías que conviven con un anacronismo constante en el ejercicio de lectura del espectador. La contemplación de 24 Hour Psycho (1993) adquiere una extraña temporalidad de resistencia, que el espectador asume como emancipación a los sistemas y regímenes hegemónicos de visualidad que se perpetúan en la pieza original. Y es ahí, en esa operación, donde el espectador abandona la figura de intérprete y se adueña de un cúmulo de imágenes para construir su propia traducción. Es lo que Jacques Rancière (Rancière, 2005) ha denominado "espectador emancipado". Esa decisión, es una decisión política donde el artista ha depositado los elementos para activar una temporalidad crítica y de este modo, formular un "despiece" de sus prerrogativas. Estas temporalidades específicas de realidad se realizan mediante un planteamiento dialógico que reformula las relaciones existentes entre las formas, los tiempos y su normatividad crítica. Consecuentemente, las condiciones de posibilidad y las potencialidades desplegadas serán el caldo de cultivo de nuevas radicalidades, no adscritas al sistema hegemónico de la visualidad.

Por otro lado, la disposición espacial de 24 Hour Psycho (1993) permite situar un tiempo presente en la recepción y el espacio físico que habita la instalación. Kate Mondloch (Mondloch, 2010) contrasta toda una serie de trabajos que desde los años sesenta hasta la actualidad trabajan con la pantalla como elemento sustancial de sus 
propuestas. A este respecto, ella define el trabajo de Douglas Gordon como "instalaciones de tiempo", donde experimentamos "muchos tiempos al mismo tiempo". Es decir, donde se produce un sistema heterocrónico de arquitecturas temporales que no se ejecutan en un tiempo concreto, sino que crean cambios y permanencias estructurales generando un nuevo tiempo en sí mismo. Asimismo, podemos situar un tiempo presente, un "afuera de anacronismo" en 24 Hour Psycho, sobre la disposición espacial de la instalación. En la medida que construye un campo de visión donde la emisión (sin sonido) se produce sobre una pantalla translúcida, a ambos lados de la misma. El espectador al aproximarse a la pantalla es visto por los espectadores situados al otro lado, ya que circunda la pieza en una exploración perimetral.

El tiempo de exploración de la instalación, o lo que Peter Osborne (Osborne, 2008) ha llamado "la recepción distraída", conjuga una dialéctica de la atención y una dialéctica de la distracción que muestra el carácter contextual que toda obra incorpora en su lógica de producción. Y, consecuentemente, esta lógica de producción de la obra de arte incorpora estrategias de consumo mercantil que produce espectadores que desarrollan una visualidad temporal de consumidores activos, que no está muy alejada de los procesos económicos desarrollados por el mercado. Llegados a este punto, habría que preguntarse si Douglas Gordon en 24 Hour Psycho (1993), construye con el autocuestionamiento y la autorreflexión a la que sitúa al espectador, las condiciones de recepción de la obra, mediante contradicciones que adquieren la categoría de proceso de producción. Esto significa trabajar dentro de la estructura económica y al mismo tiempo cuestionar sus propios objetivos, para explorar las posibilidades tanto de cooptación como de resistencia.

\section{El desplazamiento del foco de atención}

Una de las características más pertinentes en el trabajo de Douglas Gordon consiste en prescindir de una estructura temporal continua, incorporando planos fijos y prolongados, movimientos de cámara circulares en flotación o angulaciones desconcertantes que ejecuta con un modelo visual analítico. Este desplazamiento del foco de atención inherente en sus imágenes, da como resultado un imaginario donde el aislamiento de partes singulares del objeto de filmación, revela las propiedades emocionales de la totalidad del objeto explorado. La táctica de Gordon se centra en aislar fragmentos, sobredimensionándolos en encuadres "a toda pantalla" y, de este modo, convierte el fragmento en una entidad autónoma que el observador percibe como singularidad. A este respecto, Play Dead; Real Time (2003) es una instalación que se conforma con un monitor de dimensiones variables y dos pantallas lo suficientemente grandes para que el elefante filmado se proyecte a escala natural. 


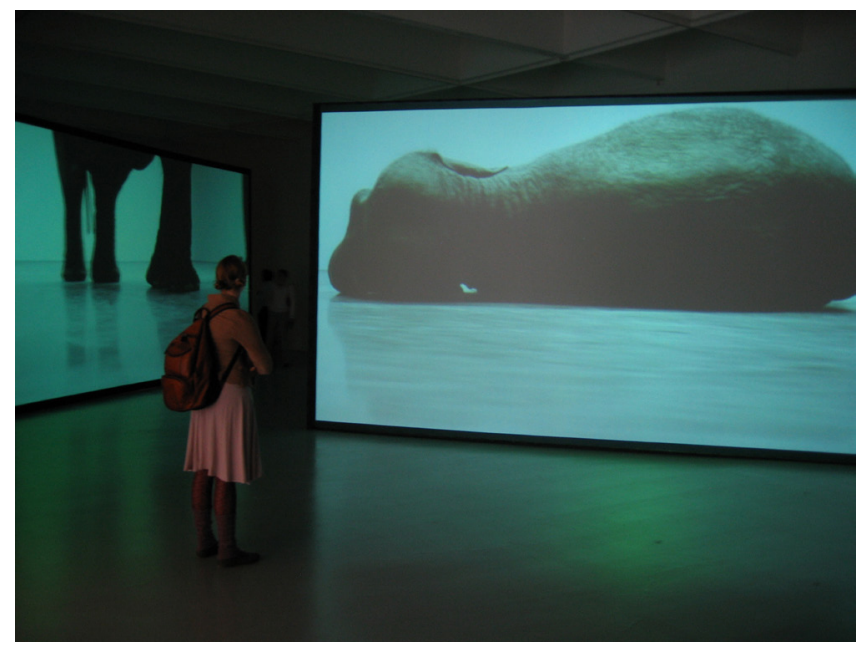

Figura 3. Douglas Gordon, Play Dead; Real Time, 2003.

(Imagen recuperada de Internet, de: http://www.flickr.com/photos/evan_m/443486560/sizes/o/in/photostream $/>$ )

Klaus Biesenbach (Biesenbach, 2007) explica que la obra está basada en un hecho real. En 1903 un elefante que había matado a tres personas fue electrocutado en Coney Island en Nueva York. El procedimiento fue filmado por la Edison Manufacturing Company. La película, de un minuto de duración, se convirtió en una maravilla itinerante, reproduciendo el espectáculo en tamaño real y en su velocidad original. El elefante empleado por Douglas Gordon fue trasladado a la galería Gagosian en Nueva York, donde se filmó mientras obedecía sus instrucciones. El elefante, de nombre Minnie, aparece en la filmación caminando, desplomándose y haciéndose el muerto. El foco de atención encuadra en todas las pantallas: ahora las patas anómalas del animal; ahora la trompa serpenteante; ahora la frente bulbosa, y de repente, un ojo brillante y móvil que nos interroga. Con el elefante de pie, petrificado, la trompa descolgada hacia el suelo, la cámara comienza a dar vueltas en torno a él, como si de un monumento se tratara. Un monumento que se transforma en una escultura fílmica, esculpiendo el tiempo cinematográfico y absorbiendo la percepción del espectador hacia una dimensión puramente estética. Paradójicamente, en Play Dead; Real Time (2003) Douglas Gordon estira la imagen hasta "sostenerla", produciendo un colapso visual del movimiento de esta, para provocar en el espectador una atención renovada, una especie de arqueología temporal que confiere a la instalación un marco temporal que no difieren mucho del marco espacial de la escultura.

Pero hay otro desplazamiento del foco de atención que me parece sumamente interesante de explorar. Me refiero al desplazamiento del foco del observador, del espectador y de las audiencias. En el caso de Douglas Gordon, la posición del observador fragmenta y modifica la narrativa de la pieza desde la propia aprehensión de la misma. El observador sintetiza la información en el proceso de observación de las imágenes, y en este ejercicio de captación es interpelado por la temporalidad que proponen, la disposición espacial de la pieza y la fragmentación visual de los focos 
de emisión. La captura de imágenes por parte del espectador, que se dan de forma simultánea en varias pantallas, le obliga a construir la narrativa operando un cambio de paradigma que introduce la atención-concentración en la recepción visual. Bajo tales circunstancias, las obras de Gordon desarrollan una retórica analítica que desafía el "tiempo de instalación" mencionado por Birbaum (Birbaum, 2005). En la medida que el reto de la recepción interpela al espectador a participar en la construcción de la obra; y a convertirse en participante activo de la misma mediante su transitividad. Una transitividad en donde el comienzo y fin de las piezas no están condicionadas por una narrativa lineal y una temporalidad monocrónica, sino meramente aleatoria. Pero además, la duración de muchas de las piezas de Gordon transgrede el tiempo de percepción posible de cualquier espectador. Hay que observar aquí, no sólo $24 \mathrm{Hour}$ Psycho (1993), sino piezas como 5 year Drive-By (1992), una copia de la película Centauros del desierto pensada para ajustarse al tiempo real de cinco años, y que justifican este razonamiento.

Por tanto, como ha apuntado Dominique Païni (Païni, 2000), el espectador frente a una sola pantalla se muestra cautivo, inmóvil y posicionado frontalmente. Sin embargo, la multiplicidad de pantallas otorga al espectador la duración en el espacio físico y el tiempo de la narración. De este modo, "el tiempo de visión" que menciona Kate Mondloch (Mondloch, 2010) está íntimamente relacionado con una idea de espectador que no es un mero receptor del impulso pedagógico de los artistas críticos, sino que, son intérpretes y reproductores de lo crítico y asumen posiciones en las que las identidades, lejos de licuarse dentro de la eventualidad de las piezas, reproducen formas críticas. El resultado es un intercambio de tipo experimental entre las personas involucradas, entre una idea de público y otra de acontecimiento, en la que se propone la relación y el encuentro entre ambos. Este intercambio experimental desarrollado en la "estética relacional" de Nicolas Bourriaud (Bourriaud, 1998), establece relaciones con un grado de implicación del espectador de manera variable y aleatoria. Y las comunidades implicadas adoptan una posición consensual que tiene evidentes similitudes con la animación cultural. Estas propuestas relacionales prometen una fraternidad cultural que nos redima de nuestro individualismo autista. Sin embargo, cabría preguntarse en qué medida esos "pseudocontactos" se hacen de la mano de las instituciones y obedecen a una gestión de productos culturales donde la institución distribuye lo "crítico".

Siguiendo a Simon Sheikh (Sheik, 2006) vemos que la "crítica institucional" a comienzos de los setenta define el método crítico como una práctica artística. Práctica artística que se vio expandida hasta incluir al artista. Es decir, la crítica institucional fue una práctica ejercida por artistas y dirigida "contra" las instituciones. La institución se planteaba como un problema para el colectivo de artistas. Pero en los años noventa se produce un cambio paradigmático donde mediante el autocuestionamiento y la autorreflexión se intentan crear instituciones críticas. En consecuencia, muchos de los artistas de los noventa implicados en lo que se dio en llamar estética relacional, como Douglas Gordon, son acusados de una complicidad y resistencia insuficiente a los procesos económicos desarrollados por el mercado y también su crítica institucional es tachada de una complicidad crítica obsoleta. Así, la crítica institucional desarrollada en el trabajo de Douglas Gordon modula su producción artística hacia 
una "semiautonomía" en la que las contradicciones adquieren la categoría de proceso de producción.

\section{Conclusiones}

La estrategia de Gordon se centra en desarrollar una interacción con el espectador, empleando elementos representacionales "desafectados". Aquí, toda omisión de afectividad se encuentra latente en la escenificación presentada, en la situación construida y en la visualidad alterada, y ésta será captada, incorporada y reconstruida por el propio espectador. Esto trae consigo una autorreflexividad que cuestiona los valores y roles predeterminados. Permitiendo así al artista introducir el conflicto y la contradicción como una forma contingente. Este conflicto no está mediado por el consenso textual, sino por abstracciones que tienen que encontrar su lugar en la representación. Estas políticas de abstracción, por utilizar un término de Critchley (Critchley, 2010), generan nuevas potencialidades y formas utópicas en desarrollo. Hay intentos de este procedimiento en los trabajos de Douglas Gordon, al articular maniobras de descentramiento y dobles movimientos continuos, que hacen que se produzca un movimiento de paralaje. Así, la contradicción y los antagonismos quedan expuestos. Como ha señalado Miguel Ángel Hernández-Navarro: “Quizá sea ahí, en los puntos ciegos, en los vacíos de significado, donde únicamente puede tener lugar la resistencia, donde el sujeto puede emplazarse junto a la multitud [...]" (Hernández-Navarro, 2007, pp. 45-46)

Estoy convencido de que el deseo y los afectos no normativizados ejercen un gran poder en la transformación efectiva de los modos de vida. Y, consecuentemente, se configuran nuevos espacios de aprehensión del mundo, que no están exentos de crítica y resistencia eficaz a la dominación por parte de las estructuras de poder que configuran el capitalismo emocional normativizado. Pero las resistencias hoy día han adoptado formas muy flexibles. En una cultura que asume toda reivindicación, sin ejecutar un análisis cultural, nos encontramos que las resistencias son insertadas por el poder dominante como creación de contenidos a gestionar por los parámetros del hiperconsumo.

Finalmente, el trabajo de Douglas Gordon nos aparece paradigmático, ya que realiza una inmersión en los procesos cognitivos adheridos a la memoria del espectador. Las preguntas que formula en sus trabajos se vehiculan desde una posición de productor artístico, de artista. Y, inevitablemente, toman en cuenta este capitalismo tardío, para la creación de estructuras semióticas, capaces de filtrarse ante una concepción adulterada de los productos culturales. Por tanto, configurar un trabajo artístico donde se despliegue y cuestione lo textual-racional y lo intuitivo-visual bajo parámetros que produzcan pensamiento, mediante esquemas perceptivos y sensoriales que dialoguen con los órdenes hegemónicos de la visibilidad, con lo enigmático y extraño, con la ocultación y desocultación de significados, con la precariedad y fragilidad del sujeto social, y con cuestiones espacio-temporales como garantes de análisis crítico de las imágenes, han sido, básicamente, las vías de trabajo que me han interesado explorar en la producción artística de Douglas Gordon. 


\section{Referencias}

Badiou, A. (1999). El ser y el acontecimiento. Buenos Aires: Manantial.

Bal, M. (2009). Narratology: Introduction to the Theory of Narrative, Toronto: University of Toronto Press.

Bal, M. (2001). Looking In: The Art of Viewing. Amsterdam: G \& B Arts Internacional.

Biesenbach, K. (2007). Douglas Gordon, Timeline (Linea de tiempo). Recuperado el 10 de septiembre 2012, de: http://www.malba.org.ar/web/prensa det.php?id=91.

Birnbaum, D. (2005). Chronology. Nueva York: Lukas \& Steinberg.

Bourriaud, N. (1998). Estética relacional. Buenos Aires: Adriana Hidalgo.

Critchley, S. (2010). El futuro del pensamiento radical. Estudios visuales, núm. 7, enero, pp. 68-79. Murcia: Cendeac.

Buck-Morss, S. (2005). Estudios visuales e imaginación global. En Brea, José Luis (coord.) La epistemología de la visualidad en la era de la globalización, pp.145-160. Madrid: Akal/ARCO.

Hernández-Navarro, M. Á. (2007). Jesús Segura: la espacialidad desbordada. En Segura, J., Stereo, pp. 45-46, Murcia: Ed. CARM.

Krauss, R. (1998). Pasajes de la escultura moderna. Madrid: Akal.

Lipovetsky, G. y Charles, S. (2006). Los tiempos hipermodernos. Barcelona: Anagrama.

Mondloch, K. (2010). Screens: Viewing Media Instalation Art. Minneapolis: University of Minnesota Press.

Osborne, P. (2008). El arte más allá de la Estética. Murcia: Ad Literam, Cendeac.

Païni, D. (2000). Le retour du flâneur / The Return of the Flaneur. Art Press, núm. 255, marzo, pp. 33-41.

Rancière, J. (2005). Sobre políticas estéticas. Barcelona: Universidad Autónoma de Barcelona.

Sheikh, S. (2006). Notas sobre crítica institucional. Recuperado el 28 de septiembre, de: http://transform.eipcp.net/transversal/0106/sheikh/es\#redir. 2012. 